\section{The importance of autopsy after failed delivery room resuscitation}

This female infant was born at 34 weeks of gestation by spontaneous vaginal delivery following increasing polyhydramnios and premature rupture of membranes. At 22 weeks of gestation, a left-sided diaphragmatic hernia with minimal mediastinal shift and a favourable head-to-lung ratio had been diagnosed. After delivery, following a short period of bag-mask ventilation with apparently appropriate chest excursions, oro-tracheal intubation was performed without difficulty by a senior neonatologist.
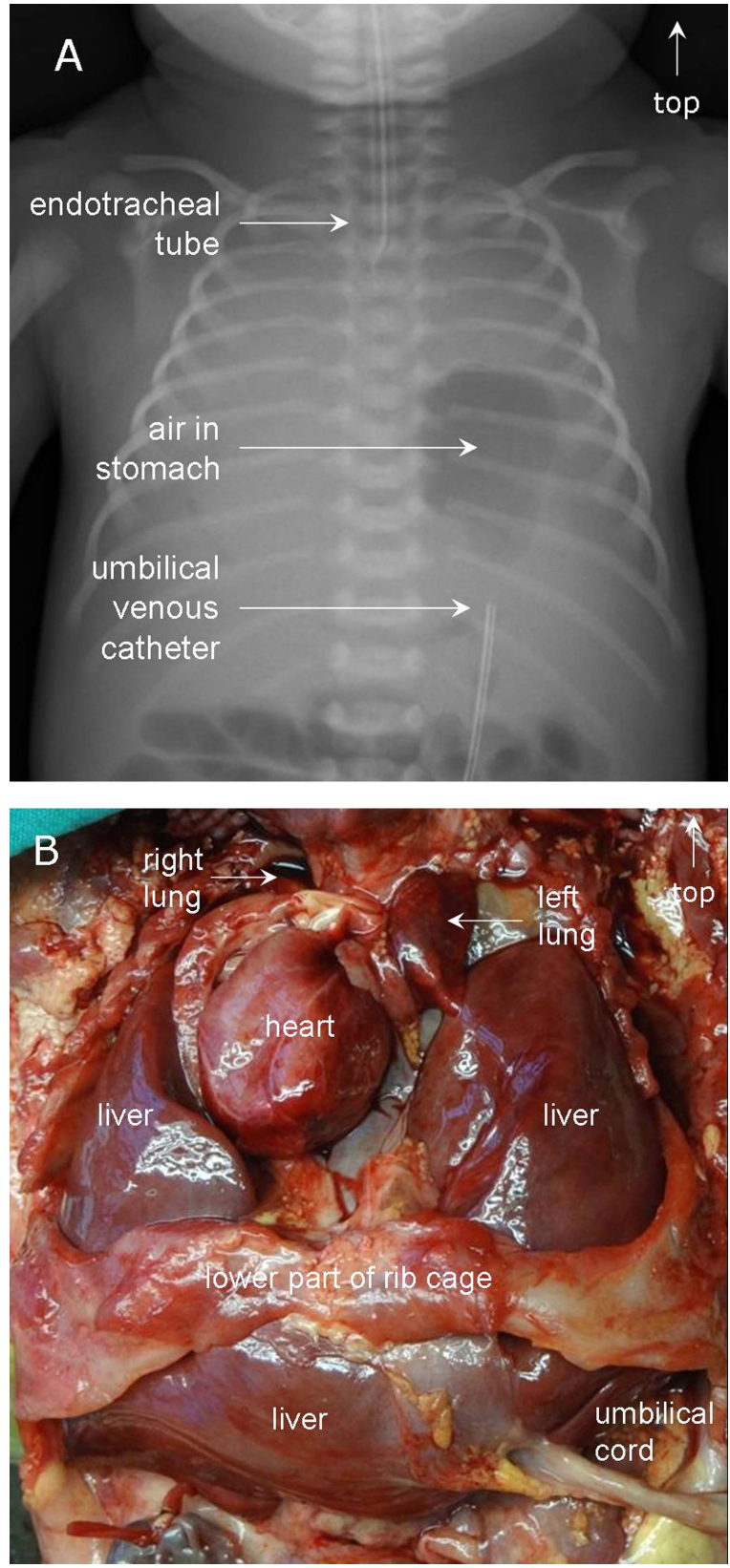

Figure 1 (A) Postmortem chest radiograph showing complete absence of lung aeration; (B) Autopsy demonstrating bilateral herniation of liver lobes and severe pulmonary hypoplasia.
When no chest excursions were visible despite high inspiratory pressures, endotracheal tube malposition was assumed and bag-mask ventilation was restarted. Although chest movements were again noted, the infant's heart rate and transcutaneous oxygen saturation did not improve. Additional intubation and ventilation attempts remained unsuccessful, and the infant died despite extended resuscitation efforts.

Because chest excursions were noted during bag-mask ventilation, but absent when ventilation was attempted through an endotracheal tube, tracheal agenesis with oesophago-tracheal fistula was suspected. However, a postmortem chest $\mathrm{x}$-ray showed air in the herniated stomach but no lung aeration (figure 1A), and at autopsy, bilateral diaphragmatic agenesis with $\mathrm{u}$-shaped liver herniation and severe pulmonary hypoplasia incompatible with life were demonstrated (figure 1B). In addition, there was a cloacal malformation. Apparently, the herniated liver had been misinterpreted as lung tissue on prenatal ultrasound examination because of comparable echodensity of liver and fluid-filled fetal lungs. The lack of a significant mediastinal shift was felt to support the impression of a small hernia, but obviously was due to bilateral herniation.

The autopsy findings in our patient fully explained the observations made during resuscitation and clarified why resuscitation was doomed to fail. This information was of utmost importance both to the parents as well as the members of the resuscitation team.

\section{Thomas M Berger, ${ }^{1}$ Martin Jöhr ${ }^{2}$}

${ }^{1}$ Neonatal and Pediatric Intensive Care Unit, Children's Hospital of Lucerne, Lucerne, Switzerland

${ }^{2}$ Department of Pediatric Anesthesia, Children's Hospital of Lucerne, Lucerne, Switzerland

Correspondence to Professor Thomas M Berger, Neonatal and Pediatric Intensive Care Unit, Children's Hospital of Lucerne, Lucerne $\mathrm{CH}-6000$, Switzerland; thomas. berger@luks.ch

Contributors The manuscript draft and the figures were prepared by the first author (TMB); the second author (MJ) reviewed the manuscript and made suggestions for improvements. Both authors approved of the final manuscript. The first author (TMB) is responsible for the overall content as guarantor.

Competing interests None.

Patient consent Obtained.

Provenance and peer review Not commissioned; externally peer reviewed.
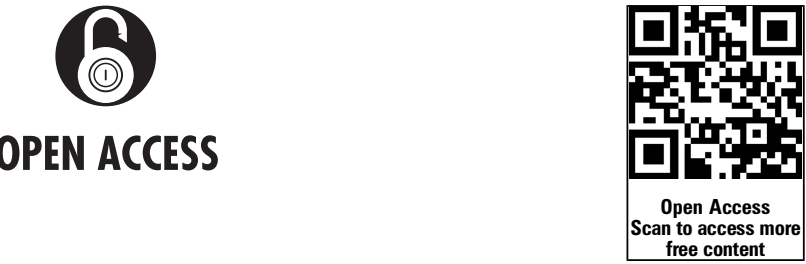

Open Access This is an Open Access article distributed in accordance with the Creative Commons Attribution Non Commercial (CC BY-NC 3.0) license, which permits others to distribute, remix, adapt, build upon this work non-commercially, and license their derivative works on different terms, provided the original work is properly cited and the use is non-commercial. See: http://creativecommons.org/ licenses/by-nc/3.0/

To cite Berger TM, Jöhr M. Arch Dis Child Fetal Neonatal Ed 2013;98:F504.

Received 9 September 2012

Revised 30 October 2012

Accepted 3 January 2013

Published Online First 24 January 2013

Arch Dis Child Fetal Neonatal Ed 2013;98:F504.

doi:10.1136/archdischild-2012-302988 